\title{
Doctoral Support Networks: characteristics and associa- tions with research conditions and identity development
} Redes de apoyo doctoral: características y relaciones con las condiciones de investigación e identidad

\author{
Núria Suñé-Soler \\ Universitat Ramon Llull \\ Carles Monereo Font \\ Autonomous University of Barcelona
}

\begin{abstract}
Doctoral candidates rely on diverse individuals to cope with the challenges of their doctoral trajectory. In this article we define Doctoral Support Networks (DSNs) as the group of individuals with whom the doctoral candidate intentionally collaborates in order to deal with the problems and difficulties of the doctorate. We aim to explore the characteristics of this type of networks and their relationships with doctoral program conditions and researcher identity development. Results from a cluster analysis identified two groups of doctoral candidates based on the characteristics of their network: those with Distributed and Active DSNs (56.8\%) and those with Reduced and Passive DSNs (43.2\%). The first group reported more frequent interactions with a wider range of individuals from both academic and extra-academic contexts, higher levels of emotional support and direct advice to cope with doctoral challenges and difficulties, and a higher level of identification with the researcher position.
\end{abstract}

Keywords: Graduate education; Social support; Doctoral candidates; Dialogical self theory

\section{Resumen}

Los estudiantes de doctorado colaboran con múltiples personas para afrontar los retos de la trayectoria. En este artículo definimos las Redes de Apoyo Doctoral (RAD) como el grupo de individuos que colabora con el doctorando para superar los problemas y dificultades del doctorado. Nuestro objetivo es explorar las características de este tipo de redes y sus relaciones con las condiciones del programa de doctorado y el desarrollo de la identidad como investigador. Los resultados de nuestro estudio identifican dos tipos de RAD ("distribuidas y activas" versus "reducidas y pasivas") que manifiestan relaciones significativas con las demás variables de análisis.

Palabras clave: Educación de Postgrado; Apoyo Social; Estudiantes de doctorado; Teoría del Self Dialógico 


\section{INTRODUCTION}

\section{Challenges and difficulties in doctoral trajectories}

The doctoral trajectory is not a linear process but a journey with emotional highs and lows in which progress mainly depends on the management of unexpected challenges and difficulties. Previous studies associated these challenges to problems with socialization and integration into the scientific community, supervisory relationship, balance between work and personal life, motivation and attribution of meaning, and access to resources (Castelló, Pardo, SalaBubaré \& Suñe-Soler, 2017; McAlpine, 2013; McAlpine, Paulson, Gonsalves \& Jazvac-Martek, 2012; Pyhältö, Toom, Stubb \& Lonka, 2012; Turner, 2015). The effects of these challenges are well documented. When the right conditions are met, they can become important sources of motivation, learning and development (Pyhältö, Stubb \& Lonka, 2009; Stubb, Pyhältö \& Lonka, 2011). However, if the doctoral student feels unable to cope with them, they grow into tensions that hinder progress, generate negative emotions, and reduce engagement and wellbeing (McAlpine, 2013; Pyhältö et al., 2012).

The chronification of unresolved difficulties is also known to cause stress, exhaustion and attrition in doctoral candidates (Pyhältö et al., 2012; Jairam and Kahl, 2012), a situation further aggravated by a work environment with progressively higher levels of job insecurity (Biron, Brun \& Ivers, 2008; Walsh \& Lee, 2015). Indeed, a recent study shows that a third of doctoral candidates experience psychological distress and are at risk of having or developing common psychiatric disorders such as anxiety and depression during the doctorate (Levecque et al., 2017). The severity of this ratio is coherent with the high dropout rates that characterize doctoral studies: $50 \%$ at the international level (Ali \& Kohun 2006; Gardner, 2009) rising to $70-90 \%$ in countries like Catalonia, Spain (Castelló et al., 2017; de Miguel Díaz, 2010).

To better understand how these challenges and difficulties are experienced and managed by doctoral candidates, research has traditionally focused on the supervisor-student relationship. Yet, recently, some authors have pointed out that an exclusive focus on this dyad, although relevant, is of limited scope (Baker \& Pifer, 2011; Hopwood, 2010b; McAlpine \& McKinnon, 2013; Sweitzer, 2008, 2009). Supervisors are sometimes unaware of candidates' struggles, either because candidates might feel uncomfortable about sharing certain issues with them or because the student-supervisor relationship is precisely the main focus of tension (Ali \& Kohun, 2007; Hopwood, 2010b; McAlpine, 2013). Relatedly, Marian Jazvac-Martek, Shuhua Chen and Lynn McAlpine (2011) found that only $32 \%$ of doctoral candidates identified the supervisor as the most important 
external position for their progress while the rest rely on a diverse range of other individuals to advance in their doctorate (e. g. peers, family, friends or themselves).

In this line, several studies have explored the characteristics of doctoral candidates' networks and their influence in several dimensions of the doctorate. Doctoral networks are usually composed of members from diverse communities, both academic-e.g. supervisor, peers, faculty and team colleagues-and extra-academic-e.g. family, friends and other professionals-(Baker \& Lattuca, 2010; Baker \& Pifer, 2011; Coromina, Capó, Guia \& Coenders, 2011; Hopwood, 2010a, 2010b; Jairan and Kahl, 2012; Jazvac-Martek, Chen \& McAlpine, 2011; Pilbeam \& Denyer, 2009; Sweitzer, 2008, 2009). There are different types of support (e. g. emotional, psychosocial, informational, professional and instrumental) that $\mathrm{PhD}$ candidates can expect from alters with specific social position (Agneessens, Waege \& Lievens, 2006; Jairam \& Kahl, 2012).

Doctoral networks play a critical role as mediators of learning (Hopwood, 2010a, 2010b) and are highly related to persistence, motivation, production and professional success (Coromina et al., 2011; de Janasz \& Sullivan, 2004; Goller \& Harteis, 2014; Hopwood, 2010b). PhD candidates with more supportive relationships experience fewer difficulties with their academic progress and show faster completion-times (Jairam \& Kahl, 2012; Pyhältö and Keskinen, 2012). Moreover, those who receive more social and emotional support report lower levels of stress and psychological problems and higher levels of wellbeing and social integration (Agneesseens, Waege \& Lievens, 2006). Doctoral networks also socialize aspiring members, regulate inclusion, construct expectations about roles and provide meaning and professional identity development (Baker \& Pifer, 2011). These studies indicate that networking (i.e. the ability to develop and manage relationships with others who have the potential to support our careers; Forret \& Dougherty, 2004) and relational agency (i.e. the ability to engage and collaborate with others in order to interpret and act on the object of our interactions in enhanced ways; Edwards and D'Arcy, 2004; Edwards, 2005; Pyhältö and Keskinen, 2012) become critical to achieving success and wellbeing during the doctorate and may also be decisive competences for identity development.

\section{DOCTORAL SUPPORT NETWORKS AND RESEARCHER IDENTITY DEVELOPMENT}

During the doctorate is expected that doctoral candidates further develop their identity through the consolidation of a researcher I-position. From Dialogical Self Theory (Hermans, 2001a; Hermans \& Hermans-Konopka, 2010; Meijers \& Hermans, 2018) doctoral candidates' identity might be re-conceptualized as an 
interconnected multiplicity of autonomous I-positions reflecting the participation of the individual in broader social communities while doing the doctorate. As spatial-relational acts, I-positions are specific situation-dependent versions of the doctoral candidate's identity-i.e. ways of addressing one-self toward other positions which emerge from specific context demands-in a continuous dialogical interchange with each other (Hermans, 2018; Hermans \& HermansKonopka, 2010). Different tasks generate different I-positions, but also different others may do so. In this sense, I-positions may be internal (e. g. I as a researcher, I as a doctoral candidate, I as a student, I as a mother), associated to specific activity spheres, functions and responsibilities; and external (e. g. my supervisor, my team, my friends, my daughter), so that significant others' perspectives, views and voices are also integrated into doctoral candidate's extended self (Hermans, 2001b; James, 1890). Doctoral candidates' identity-as dialogical, distributed and context-dependent-is recursively involved in processes of positioning and counter-positioning with some positions becoming temporary more dominant or powerful depending on the contingencies of the situation at hand (Hermans, 2018).

Several factors may facilitate the development of a specific I-position as a researcher. First, a special kind of I-positions, promoters (Hermans, 2018; Raggatt, 2015) have the potential to organize and give direction to groups of Ipositions and stimulate the development of the self. They push the self into particular innovative directions, facilitating the emergence of more specialized (new) I-positions and integrating them within the previous self repertoire in order to cope with the demands of a specific domain (in this case, e.g. the research and academic communities). Promoters have context-dependent nature and can exist in the internal and external domain of the self. Some significant people may enter the extended domain of the self (e.g. My supervisor) because they are seen as adding value to the community or as having a powerful position and become relevant promoters for self-development. These external promoters in the self may evolve into similar promoters in the internal domain (e.g. I as a dedicated researcher identifying with my supervisor) or become promoters that develop in the opposite direction (e.g. I as a democratic leader to overcome the limitations of my boss) (Hermans, 2016). Over the doctoral trajectory, promoters may change and show up as significantly different. In order to develop and consolidate a researcher I-position, PhD candidates' must have access to well-aligned promoter positions, whether internal or external, with the capacity of produce a diverse range of more specialized and competent positions at the same time that they contribute to the democratic organization of the self (Hermans, 2018). 
Second, the challenges and difficulties of the doctoral path may produce enough levels of uncertainty and tension in $\mathrm{PhD}$ candidates' self to open the door to change and innovation in their position repertoires (Hermans, 2018; Monereo, 2019). These innovative impulses of the environment together with a self with flexible boundaries may generate a diverse range of new specialized Ipositions to solve the tension produced by the doctoral event. Coping with a stressful situation is expected to be successful if the PhD student has access to alternative I-positions with the ability and power to solve the emotional, social or technical challenges that the specific situation evokes. These challenges and difficulties may, in the end, reinforce the position repertoire of PhD candidates and become the arena to enrich, test and validate the fit of their researcher Iposition.

Finally, precisely, significant others with whom the PhD student's collaborating to cope with doctoral challenges and difficulties may develop into external Ipositions of the self with specific meanings and perceptions about what it means to be a researcher. During the interactions about these doctoral events, $\mathrm{PhD}$ candidates not only position themselves toward the event but are also positioned by others (Hermans, 2001a). They experience themselves through the positioning eyes of these significant others (e.g. supervisor, peers, friends) and react to this external positioning with a counter-positioning that may also become established in their identity repertoire (Hermans, 2018). On the other hand, as an external I-positions, they become sources of identity even when they are not physically present. Dependent on their expertise, power, and demands of the situation, significant others from doctoral networks may finally become external promoter positions with a leadership status to encourage and modulate the development of PhD student' researcher I-position. Given the complexity, diversity and cross-domain of the challenges and difficulties of the doctoral path, it may be decisive to have access to the wide range of potential promoters that doctoral networks provide.

For this study, we define Doctoral Support Networks (DSNs) as the group of individuals (i.e. external positions) with whom the doctoral candidate intentionally collaborates in order to deal with the difficulties of the doctoral trajectory. Although the effects of academic networks on the progress, socialization and wellbeing of doctoral candidates are well documented, relatively little is known about the impact of broader networks in the development of a researcher I-position. Moreover, there is also a need to explore further how specific research conditions may hinder or facilitate the development of adaptive and positive DSNs.

We aim to fill these gaps answering the following research questions: 
1. What are the main characteristics of DSNs?

2. What are the relationships between DSNs characteristics and Doctoral Program's conditions?

3. What are the relationships between DSNs characteristics and the development of a researcher I-position?

\section{METHOD}

Our methodology was based on an interpretative, quantitative dominant mixedmethod design (Gibson, 2016; Johnson, Onwuegbuzie \& Turner, 2007; Riazi \& Candlin, 2014). The argumentation behind was to broaden the scope of data collection and analyses, to increase the validity of measures through triangulation, and to enhance the capacity for the interpretation and elaboration of the results (Edmonson \& McManus, 2007; Greene, Caracelli \& Graham, 1989; Molina-Azorin, 2016; Tashakkori \& Teddlie, 2010).

\section{Context and participants}

Doctoral education in Catalonia is mainly regulated by the Royal Decree 99/2011, which introduced some changes based on Bologna (1999) and Salzburg (2005) principles in order to harmonize research training in Spanish universities to the European Higher Education Area (EHEA) and European Research Area (ERA). The main innovations regarding doctoral education were (a) a limitation of the duration of doctoral studies to three years (with two possible consecutive annual extensions); (b) a new conception of doctoral candidates not just as "students" but also as "early career researchers"; (c) a specific focus on the supervisory relationship as a key element for the formation, progress and wellbeing of doctoral candidate; (d) the creation of Doctoral Schools, Academic Commissions and Doctoral tutors as new educational agents to improve the quality of doctoral training; and (e) the creation of a new assessment tool, the Doctoral Portfolio, in which doctoral candidates and supervisors must validate and proof the consecution of different milestones of doctoral candidates' trajectory at the end of each year (i.e. publications, training courses, participation in international conferences).

Participants were 149 doctoral candidates $(60.4 \%$ female; mean age $=33.9)$ from Universitat Autònoma de Barcelona (Catalonia). At the time of the study (2016), 33.5\% of the participants were enrolled in the Social Sciences; $28.9 \%$, in Health and Social Care; $21.5 \%$, in STEM; and 16.1\%, in the Arts and Humanities. Most participants $(68 \%)$ were in the initial stage of the doctorate; $21.1 \%$, in the middle stage; and $10.9 \%$, in the final stage. In relation to thesis format, $43.9 \%$ 
of participants were writing a monograph; $34.5 \%$, a compilation of articles; and $21.6 \%$, have not decided it yet. Regarding the frequency of supervisory meetings, $41.5 \%$ of participants declared having meetings once every 2 weeks; $33.3 \%$, once a month; $21.1 \%$, less than once a month; and $4.1 \%$, depending on availability or thesis progress. The average level of satisfaction with supervision was 3.79 (minimum= 1 , maximum $=5 ; S D=1.174$ ). Additionally, most participants $(60.8 \%)$ declared to participate in a research team.

\section{Data collection and analyses}

Data were collected through an on-line questionnaire with 13 questions about demographics, research conditions and identity, and DSNs characteristics (see Table 1 for further details regarding the full set of variables and response format). Web questionnaires have proved to be a valid and reliable instrument for collecting network data, especially for a population of $\mathrm{PhD}$ candidates who use the computer daily for work. For the questionnaire design, we followed the recommendations in regards to validity in Lluís Coromina and Germà Coenders (2006) who propose that ordering the items by question instead of by alters and labelling each response categories help to improve validity. The content of the items was selected from previous studies on DSN, reviewed in the first two sections.

For data analyses, firstly, we applied the principles of content analysis (Flick, von Kardoff \& Steinke, 2004; Mayring, 2004; Neuendorf, 2002) to code the open-ended questions and re-code participants' specifications for the response category "Other". We then carried out descriptive analyses and conducted kmeans cluster analysis (SPSS, v.21) to identify groups of participants based on the characteristics of their Doctoral Support Network (diversity of alters, frequency of interaction and quality of support). Finally, we performed Chisquare, Crammer's V, and independent samples $t$-tests to explore the associations and differences between clusters in the remaining variables.

\section{RESULTS}

\section{What are the main characteristics of Doctoral Support Networks (DSNs)?}

Data analyses showed that participants interact with a wide range of people to deal with the difficulties of their doctoral journey. The majority of doctoral candidates reported conversations with family member(s) (94.6\%), supervisor(s) $(81.2 \%)$, friend(s) $(76.5 \%)$, and peer(s) $(67.1 \%)$ about problems related to their doctorate. Fewer doctoral candidates reported interactions with team colleague(s) $(46.3 \%)$, extra-academic professionals (32.9\%), or faculty $(24.8 \%)$. Regarding the frequency of interaction, the external positions with whom doctor- 


\begin{tabular}{|c|c|c|c|}
\hline Category & \multicolumn{2}{|c|}{ Variables } & Response format (codes) \\
\hline \multirow[b]{2}{*}{ Demographic } & \multicolumn{2}{|l|}{ Age } & Open-ended question - number format \\
\hline & \multicolumn{2}{|l|}{ Gender } & $\begin{array}{l}\text { Categorized question (Female, Male, Oth- } \\
\left.e r^{*}\right)\end{array}$ \\
\hline \multirow{8}{*}{$\begin{array}{l}\text { Research } \\
\text { conditions }\end{array}$} & \multicolumn{2}{|l|}{ Discipline } & Open-ended question \\
\hline & \multicolumn{2}{|l|}{ Year } & $\begin{array}{l}\text { Categorized question (First, Second, } \\
\text { Third, Other) }\end{array}$ \\
\hline & \multicolumn{2}{|l|}{ Thesis format } & $\begin{array}{l}\text { Categorized question (Monograph, Sum- } \\
\text { mary of articles, I don't know) }\end{array}$ \\
\hline & \multicolumn{2}{|c|}{ Frequency of supervision } & $\begin{array}{l}\text { Categorized question (Once a week, Twice } \\
\text { a month, Once a month, Other) }\end{array}$ \\
\hline & \multicolumn{2}{|c|}{ Level of satisfaction with supervision } & Likert scale 1-5 \\
\hline & \multicolumn{2}{|c|}{ Participation in the research team } & Categorized question (Yes, No) \\
\hline & \multicolumn{2}{|c|}{$\begin{array}{l}\text { Identification with Researcher Identi- } \\
\text { ty }(\mathrm{RI})\end{array}$} & Likert scale 1-5 \\
\hline & \multicolumn{2}{|c|}{$\begin{array}{l}\text { Conceptions related to RI develop- } \\
\text { ment }\end{array}$} & Open-ended question \\
\hline \multirow{3}{*}{$\begin{array}{l}\text { Doctoral } \\
\text { Support } \\
\text { Network }\end{array}$} & $\begin{array}{l}\text { Frequency of inter- } \\
\text { action with each al- } \\
\text { ter }\end{array}$ & \multicolumn{2}{|c|}{$\begin{array}{l}\text { Combined categorized question (Family, Friends, Supervi- } \\
\text { sor/s, Peers in the same department, Peers from other de- } \\
\text { partments, Members of the research team, Faculty from } \\
\text { the same university, Faculty from different university, Ex- } \\
\text { tra-academic professionals. Other) with Likert scale (1: } \\
\text { Never, 2: Rarely; 3: Sometimes; 4: Usually; 5: Always). }\end{array}$} \\
\hline & $\begin{array}{l}\text { Type of support from } \\
\text { each alter }\end{array}$ & \multicolumn{2}{|c|}{$\begin{array}{l}\text { Combined categorized question (type of alter) and type of } \\
\text { support (Information, knowledge and strategies to solve } \\
\text { the problem (Direct Advice); and Emotional support) with } \\
\text { Likert scale (1: Never, 2: Rarely; 3: Sometimes; 4: Fre- } \\
\text { quently; 5: Always). }\end{array}$} \\
\hline & Relevance & \multicolumn{2}{|c|}{ Open-ended question } \\
\hline
\end{tabular}

* Every "Other" option could be specified by participants

Table 1. Questionnaire variables and answer type

al candidates talked more about their difficulties and problems were a supervisor(s) (mean= 3.36; $S D=1.056$ ); followed by peers (mean=3.22; $S D=1.324$ ) and friends (mean=3.14; $S D=0.923$ ). The external positions with a lower frequency of interaction were faculty members (mean=1.99; $S D=0.997$ ) (see Table 2 for further details).

These external positions provided at least two types of support: (a) direct advice about how to cope with or solve the difficulty or problem-being the main sources supervisor $(\mathrm{s}) \quad($ mean $=3.77 ; \quad S D=1.131)$ and peers (mean=3.14; $\mathrm{SD}=1.249$ ) - ; and (b) emotional assistance, mostly from friends (mean=4.15; $S D=1.039)$, family (mean=4.11; $S D=1.275)$, supervisor(s) (mean=3.70; $S D=1.281)$ 
and peers (mean=3.47; $S D=1.407$ ). On average, DSNs provided a higher frequency of emotional support than direct advice. Regarding the relevance of their DSNs, most participants $(89.4 \% ; n=101)$ explicitly declared that it played a significant role in their doctoral progress and wellbeing during the journey.

Results from K-means cluster analyses (see Table 2) identified two groups of $\mathrm{PhD}$ candidates who showed significant differences regarding the main charac-

\begin{tabular}{|c|c|c|c|c|c|c|}
\hline & \multirow{2}{*}{\multicolumn{2}{|c|}{$\begin{array}{l}\text { Frequency of interaction } \\
\text { about doctoral difficulties a }\end{array}$}} & \multicolumn{4}{|c|}{ Type of support } \\
\hline & & & \multicolumn{2}{|c|}{$\begin{array}{c}\text { Frequency of } \\
\text { emotional support }\end{array}$} & \multicolumn{2}{|c|}{$\begin{array}{l}\text { Frequency of direct } \\
\text { advice }\end{array}$} \\
\hline & Mean & SD & Mean & SD & Mean & SD \\
\hline Family & 2,91 & 1,036 & 4,11 & 1,275 & 2,62 & 1,242 \\
\hline Friends & 3,14 & ,923 & 4,15 & 1,039 & 2,87 & 1,139 \\
\hline Supervisor & 3,36 & 1,056 & 3,70 & 1,281 & 3,77 & 1,131 \\
\hline Peers & 3,22 & 1,324 & 3,47 & 1,407 & 3,14 & 1,240 \\
\hline Team colleagues & 2,49 & 1,280 & 2,64 & 1,443 & 2,61 & 1,307 \\
\hline Faculty & 1,99 & ,997 & 2,25 & 1,266 & 2,24 & 1,236 \\
\hline Professionals (EA) & 2,09 & 1,081 & 2,04 & 1,256 & 1,89 & 1,064 \\
\hline
\end{tabular}

aLikert Scale (1: never, 2: rarely, 3: sometimes, 4: frequently, 5: always)

Table 2. Mean and SD of the frequency of interaction and type of support $(n=148)$

teristics of their DSNs: diversity of external positions, frequency of interaction and type of support provided. Cluster 1, named as Distributed and Active DSNs, included 84 participants (56.8\%) who had more expansive and frequent interactions and received higher levels of both kinds of support. Cluster 2, named as Reduced and Passive DSNs, included 64 participants (43.2\%) who had fragmented networks with fewer interactions with the academic community and received lower levels of both kinds of support. As we can see in Table 3, these two groups did not show significant differences regarding the frequency of interactions with friends and other professionals of non-academic contexts.

As Figures 1 and 2 show, PhD candidates with Distributed and Active DSNs not only interact with a broader range of external positions from both the academic and non-academic contexts but also receive higher levels of direct advice and emotional support from all of them. While those candidates with Distributed and Active DSNs reported more frequent emotional assistance from both their personal (i.e. family and friends) and academic community (i.e. supervisor and peers), those with Reduced and Passive DSNs declared general lower levels of emotional guidance, especially from their academic community. Moreover, whereas candidates with Reduced and Passive DSNs only had one 
primary source of direct advice (i.e. supervisors), those with Distributed and Active DSNs receive orientations and strategies to cope with doctoral difficulties or problems from a variety of counsellors or experts, such as supervisor, peers, and team colleagues and, to a lesser extent, also friends.

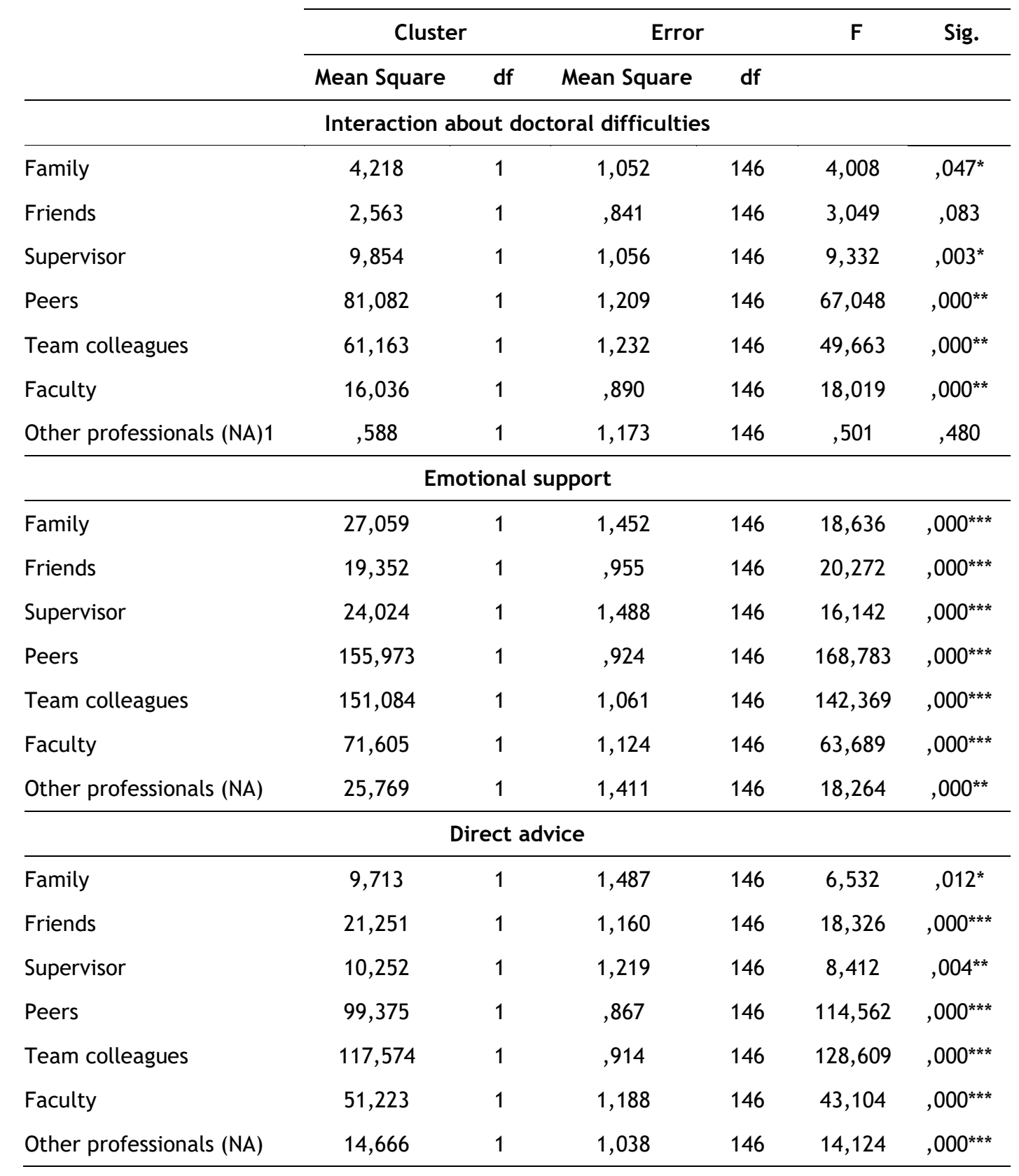

${ }^{1}$ Note: Non-academic context

Table 3. ANOVA values for K-means cluster analysis 


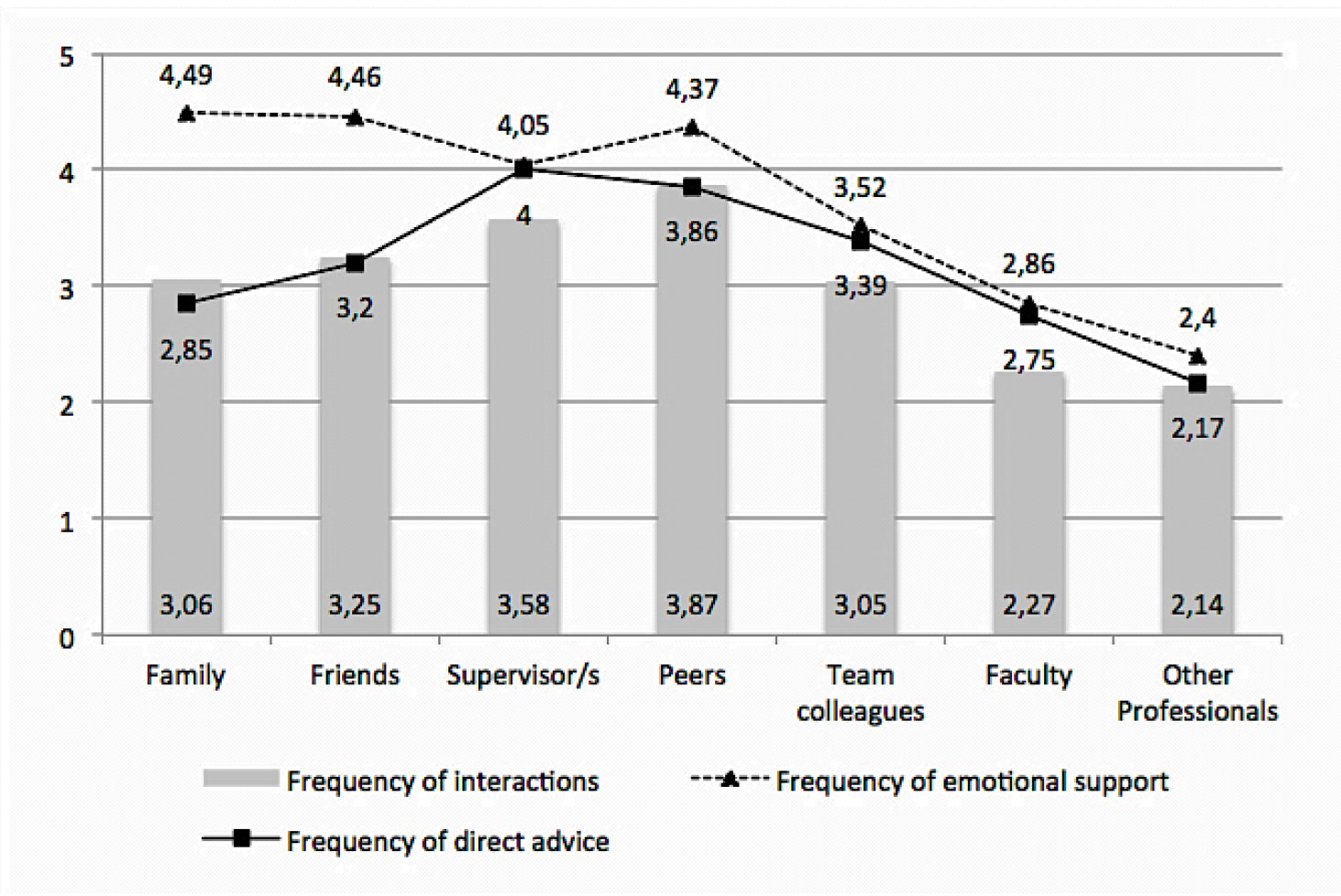

Figure 1. Mean values related to the frequency of interaction, emotional support and direct advice of those candidates with Distributed and Active DSNs (Cluster 1).

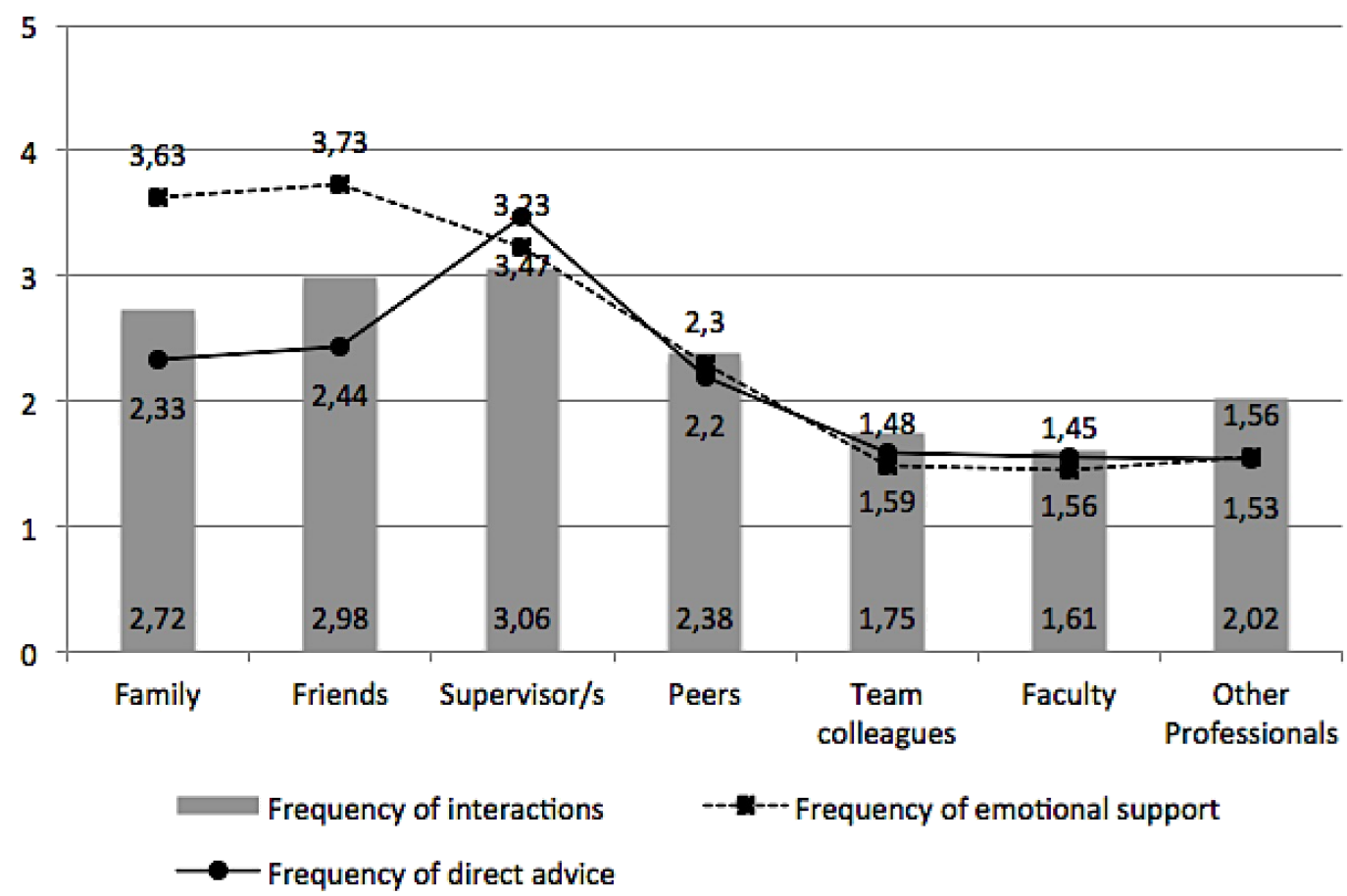

Figure 2. Mean values related to the frequency of interaction, emotional support and direct advice of those PhD candidates with Reduced and Passive DSNs (Cluster 2). 


\section{What are the relationships between DSNs characteristics and Doctoral Program's conditions?}

Chi-squared and $t$-tests (see Table 4) revealed that participants with Distributed and Active DSNs were significantly more likely to participate in a research team $(\times 2(1)=16.687, p<.000$, Cramer's $V=.336)$. Moreover, they had more frequent supervision meetings $(x 2(3)=8.886, p<0.05$, Cramer's $V=.246)$ and reported higher levels of satisfaction with supervision $(\mathrm{t}(101.942)=2.878, \mathrm{p}<$ .01 ). No differences were found related to gender, discipline, age, year, and thesis format.

\begin{tabular}{|c|c|c|c|c|}
\hline & & $\begin{array}{l}\text { Distributed and } \\
\text { Active DSNs }\end{array}$ & $\begin{array}{l}\text { Reduced and } \\
\text { Passive DSNs }\end{array}$ & \\
\hline \multirow{2}{*}{$\begin{array}{l}\text { Participation in a } \\
\text { research team } \\
(n=148)\end{array}$} & No & & $35, z=4.1$ & \multirow{2}{*}{$\begin{array}{l}\mathrm{x}^{2}(1)=16.687 ; \\
\text { Cramer's V=.336 } \\
\mathrm{p}<.000\end{array}$} \\
\hline & Yes & $66, z=4.1$ & $24, z=-4.1$ & \\
\hline \multirow{4}{*}{$\begin{array}{l}\text { Frequency of su- } \\
\text { pervision }(n=147)\end{array}$} & $\begin{array}{l}\text { At least twice a } \\
\text { month }\end{array}$ & $45, z=2.9$ & $16, z=-2.9$ & \multirow{4}{*}{$\begin{array}{l}x^{2}(3)=8.886 ; \\
\text { Cramer's V=.246 } \\
p=.031\end{array}$} \\
\hline & Once a month & $26, z=-1.2$ & $23, z=1.2$ & \\
\hline & $\begin{array}{l}\text { Less than once a } \\
\text { month }\end{array}$ & $14, z=-1.9$ & $17, z=1.9$ & \\
\hline & Variable & $3, z=-0.5$ & $3, z=0.5$ & \\
\hline \multicolumn{2}{|c|}{$\begin{array}{l}\text { Level of satisfaction with supervision }(n= \\
\text { 147) }\end{array}$} & $\begin{array}{c}\text { Mean }=4.02 \\
S D=1.011\end{array}$ & $\begin{array}{c}\text { Mean }=3.44 \\
S D=1.317\end{array}$ & $\begin{array}{l}t(101.942)=2.878 \\
p=.005\end{array}$ \\
\hline
\end{tabular}

Table 4. Chi-Square tests, symmetric measures and independent samples t-test of the relationships between DSNs and research conditions (SPSS, v.21)

\section{What are the relationships between DSNs characteristics and the development of a researcher I-position?}

The mean level of identification with the researcher I-position reported by the participants was 3.45 (min. $=1$, max. $=5, S D=1.145)$ ) $21 \%$ of them declared a very low or low level of identification; $25 \%$, a medium level; and $54 \%$, a high or very high level. Independent samples t-test revealed that those PhD candidates with Distributed and Active DSNs reported a significantly higher level of identification with the researcher position than those with Reduced and Passive DSNs $(\mathrm{t}(100.988)=3.519, \mathrm{p}<.005)$.

Content and descriptive analyses revealed that participants associate their level of identification with the researcher I-position to the different promoter or anti-promoter I-positions (see table 5). Particularly, doctoral candidates highlighted the I-positions "I-as-full-time-student", "I-as-a-competent-researcher", 


\begin{tabular}{|c|c|c|c|}
\hline & Frequency (\%) & & Frequency (\%) \\
\hline \multirow{4}{*}{$\begin{array}{l}\text { Promoter } \\
\text { positions } \\
\text { (drivers) }\end{array}$} & \multirow{4}{*}{63 (55.8\%) } & Dedication time: I as a full time student & $16(14.2 \%)$ \\
\hline & & $\begin{array}{l}\text { Research variables: My thesis as an interesting, } \\
\text { useful or adequate research }\end{array}$ & $15(13.3 \%)$ \\
\hline & & $\begin{array}{l}\text { Personal variables: I as a competent, experienced } \\
\text { or motivated researcher }\end{array}$ & $31(27.4 \%)$ \\
\hline & & $\begin{array}{l}\text { Community: My supportive community or supervi- } \\
\text { sor }\end{array}$ & $1(0.9 \%)$ \\
\hline \multirow{4}{*}{$\begin{array}{l}\text { Anti- } \\
\text { promoter } \\
\text { positions } \\
\text { (barriers) }\end{array}$} & \multirow{4}{*}{$50(44.2 \%)$} & Dedication time: I as a part time student & $7(6.2 \%)$ \\
\hline & & $\begin{array}{l}\text { Research variables: My thesis as poor, not inter- } \\
\text { esting or not useful research }\end{array}$ & 7 (6.2\%) \\
\hline & & $\begin{array}{l}\text { Personal variables: I as an apprentice, with lack } \\
\text { of research competences, knowledge or experi- } \\
\text { ence }\end{array}$ & $27(23.8 \%)$ \\
\hline & & $\begin{array}{l}\text { Community: My uncooperative or unsupportive } \\
\text { community or supervisor }\end{array}$ & $9(8 \%)$ \\
\hline Total & $113(100 \%)$ & Total & $113(100 \%)$ \\
\hline
\end{tabular}

Table 5. Chi-Square tests, symmetric measures and independent samples t-test of the relationships between DSNs and research conditions (SPSS, v.21)

"My-interesting-thesis", "My-useful-thesis", "My-adequate-thesis", "Mysupportive-community" and "My-supportive-supervisor" as the main drivers for the development of the I-position as researchers. On the contrary, they also identified the I-positions "I-as-part-time-student", "I-as-apprentice”, "I-as-notcompetent-researcher"; "I-as-inexperienced-researcher", "My-poor-thesis", "My-not-interesting-thesis", "My-not-useful-thesis", "My-unsupportivecommunity" and "My-unsupportive-supervisor" as the main barriers for the development of an internal I-position as researchers. Moreover, those with $\mathrm{Re}$ duced and Passive DSNs were significantly more likely to report the external Ipositions "My-unsupportive-community" and "My-unsupportive-supervisor" as the main anti-promoter I-positions $(\times 2(1)=8.253, p<0.005$, Cramer's V $=.27)$.

\section{DISCUSSION}

Our study has confirmed that doctoral candidates interact with a wide range of people to deal with challenges and difficulties of their doctoral journey. Moreover, we have identified two profiles of doctoral candidates based on the characteristics of their Doctoral Support Networks (DSNs) that showed significant differences in their level of identification with the researcher I-position. Underlying each profile, we may deduce different paradigms or models of doctor- 
al training. As our results showed, doctoral candidates with Distributed and Active DSNs interact with a broader range of external positions, receive frequent emotional assistance from both their personal and academic communities, and obtain direct advice to cope with doctoral challenges and difficulties from a wide array of experts from the academic community. We infer that these doctoral candidates benefit from a distributed supervision model (McAlpine, 2013), in which doctoral training is not individually improvised by the supervisor, but a collective responsibility in which other educational agents (i.e. peers, team colleagues and faculty members) also collaborate in training and socialization of doctoral candidates.

On the contrary, those with Reduced and Passive DSNs, reported overall fewer interactions and reduced levels of emotional assistance and direct advice, which mostly felt on the supervisor. Consistently with the findings of Krisi Pyhältö and Jenni Keskinen (2012) this significant lack of both types of support was especially significant from key figures of the academic community (i.e. peers, faculty and team colleagues). In these cases, the impossibility to participate in a research team and the unsatisfactory and infrequent supervision meetings have been proved to hinder the development of doctoral candidates' relational agency and, consequently, the emergence of more positive DSNs. Another interesting result of our study is the evidence that perceiving the relevance of networking appears to be necessary but not enough to develop Distributed and Active DSNs. Although the vast majority of participants (89\%) recognized the positive impact of networking on their doctoral progress, almost half of the doctoral candidates were not able to develop adequate DSNs. The nonexistence of a significant association between doctoral stage and the quality of the DSNs corroborates that doctoral training is not helping PhD candidates and other community members to progressively develop networking abilities and more adaptive DSNs throughout the doctorate (AQU, 2017). Furthermore, we surmise that those barriers to interact with academic figures about the emotional dimension of the doctoral journey may indicate that a prevailing culture of silence regarding the affective component of research (Cotterall, 2013) still dominates the research department of almost half of participants of our study.

Regarding the differences between the two profiles on the level of identification with the researcher I-position, our results indicate that Distributed and Active DSNs may act as a driver for the development of this specific I-positions. A possible explanation for this finding comes from the Dialogical Self Theory (Hermans, 2001a; Meijers \& Hermans, 2018). Candidates with Distributed and Active DSNs have a greater number of opportunities to interact with diverse ex- 
ternal I-positions about the significant events of their doctoral journey and, thus, to position and been positioned themselves as a (future) researchers (Hermans, 2018). These dialogical encounters may become rich spaces for the negotiation and the integration of a (developing) researcher I-position into her identity repertoire. Moreover, those doctoral candidates with Distributed and Active DSNs may also benefit of several promoter I-positions (i.e. I as a fulltime student; my thesis as an interesting, useful or adequate research; I as a competent, experienced or motivated researcher; and My supportive community or supervisor) that boost the negotiation, integration and consolidation of the researcher I-position within their self repertoire. As our results showed, even when participants highlight both internal and external I-positions, it seems that are those external I-positions linked to the university (i.e. my community and my supervisor) the ones who have more power to facilitate the development of the researcher I-position.

\section{CONCLUSIONS}

During the doctorate is expected that every doctoral candidate develops an Iposition as a researcher. In our study, we were able to demonstrate that Doctoral Support Networks (DSNs) play a significant role in the development of this specific I-position, although not all DSNs have been proved to be equally effective. Doctoral candidates with Distributed and Active DSNs manifested higher levels of identification with the researcher I-position and greater satisfaction with their doctoral training and supervision than those with Reduced and Passive DSNs. Going into more detail, the results of our research also highlighted the fundamental role of promoter and anti-promoter I-positions on identity construction. External alters who conform DSNs may be internalized as external I-positions within the dialogical self of doctoral candidates and become potent drivers or barriers for their identity development as researchers.

Unfortunately, we know that the majority of doctoral programs in Catalonia still not have among their objectives the formal training and promotion of Distributed and Active DSNs among their doctoral candidates. A prevailing dominant narrative which still conceives the doctoral path as an individual endeavour is transferring the responsibility of learning how to develop and manage DSNs almost exclusively on the intuition of doctoral candidates (McAlpine et al., 2012; Pyhältö \& Keskinen, 2012). As McAlpine (2013) argued, doctoral supervision should not be individually improvised but a collective institutional responsibility. Coordinators of Research Education (CREs) should inquire about the existence and characteristics of DSNs and, when necessary, provide to faculty members, research colleagues, supervisors and peers with the fundamental 
resources and opportunities to collaboratively support the trajectories of doctoral candidates, create and/or strengthen these networks, and become external promoter I-positions for their dialogical self-development. Moreover, doctoral programs should implement mechanisms, activities and workplaces more oriented towards optimizing the relational agency and networking possibilities of doctoral candidates, especially in those cases that individuals face specific barriers or anti-promoter I-positions (e. g. "I-as-a-part-time-student”). Promoting more Distributed and Active DSNs within the academic community not only will benefit the progress of doctoral candidates but also enhance the dialogical power and scientific advancement of the whole community.

This study was an initial exploration of DSNs and, as such, there are several limitations that need to be taken into account. In relation to the characteristics of the sample, all participants were enrolled in the same university and, although they were relatively well distributed in terms of most variables, none of them was in the first year. On the other hand, most of the network data collected were quantitative, narrowing the possibilities for analysis. Future research should conceive DSNs from a more dynamic and situated perspective (Hopwood, 2010a) and include measures about how these networks change and evolve during the doctoral journey. Also, it would be interesting to explore further how the dialogic interactions within DSNs impact on the development of diverse doctoral candidates' core I-positions (e.g. I as a researcher, teacher, practitioner, author) (Hermans \& Gieser, 2012). Furthermore, future studies should analyse in more detail the characteristics and dynamics of doctoral candidates' promoters and anti-promoters I-positions in relation to the construction and integration of their researcher identity, as well as the dialogical strategies that the individual uses in the negotiation of new I-positions within a self embedded in power dynamics and populated with other voices, meanings and previous I-positions which may be divergent (Hermans, 2016). Another interesting line of research would be the validation of training resources specially oriented to help doctoral candidates to improve their relational agency, networking abilities and identity development during the doctoral trajectory. To this aim, future studies should consider expanding the research design with more qualitative measures and collect longitudinal data of the functioning and dynamics of DSNs and the dialogical self of doctoral candidates. 


\section{REFERENCES}

Agneessens, Filip; Waege, Hans \& Lievens, John(2006). Diversity in social support by role relations: A typology. Social Networks, 28(4), 427-441. https://doi.org/10.1016/j.socnet.2005.10.001

Ali, Aazad \& Kohun, Frederick (2006). Dealing with isolation feelings in IS doctoral programs. International Journal of Doctoral Studies, 1, 21-33. https: / / doi.org/10.28945/58

AQU. (2017). La inserció laboral dels doctors i doctores de les universitats catalanes. Retrieved from http://www.aqu.cat/doc/doc_89088268_1.pdf

Baker, Vicky L. \& Lattuca, Lisa R. (2010). Developmental networks and learning: toward an interdisciplinary perspective on identity development during doctoral study. Studies in Higher Education, 35(7), 807-827. https://doi.org/10.1080/03075070903501887

Baker, Vicky L. \& Pifer, Meghan J. (2011). The role of relationships in the transition from doctoral student to independent scholar. Studies in Continuing Education, 33(1), 5-17. https: / / doi.org/10.1080/0158037X.2010.515569

Biron, Caroline; Brun, Jean-Pierre \& Ivers, Hans (2008). Extent and sources of occupational stress in university staff. Work, 30, 511-522. Retrieved form https://www.ncbi.nlm.nih.gov/pubmed/18725713

Castelló, Montserrat; Pardo, Marta; Sala-Bubaré, Anna \& Suñé-Soler, Núria (2017). Why do candidates consider dropping out of doctoral degrees? Institutional and personal factors. Higher Education, 74(6), 1053-1068. https://doi.org/10.1007/s10734-0160106-9

Coromina, Lluís; Capó, Aina; Guia, Jaume \& Coenders, Germà (2011). Effect of background, attitudinal and social network variables on PhD candidates' academic performance. A multimethod approach. Estudios Sobre Educacion, 20(20), 233-253. Retrieved from http://hdl.handle.net/10171/18419

Coromina, Lluis \& Coenders, Germà (Universitat de G. (2006). Reliability and validity of egocentered network data collected via web. A meta-analysis of multilevel multitrait multimethod studies. Social Networks, 28(3), 209-231. https: / / doi.org/10.1016/j.socnet.2005.07.006

Cotterall, Sara. (2013). More than just a brain: emotions and the doctoral experience. Higher Education Research \& Development, 32(2), 174-187. https: / / doi.org/10.1080/07294360.2012.680017

de Janasz, Suzanne C. \& Sullivan, Sherry E. (2004). Multiple mentoring in academe: Developing the professorial network. Journal of Vocational Behavior, 64(2), 263-283. https://doi.org/10.1016/j.jvb.2002.07.001

de Miguel Díaz, Mario (2010). Evaluación y mejora de los estudios de doctorado. Revista de educación, 352, 569-581. Retrieved from http://www.revistaeducacion.educacion.es/re352/re352_25.pdf

Edmonson, Amy \& McManus, Stacy E. (2007). Methodological Fit in Management Field Research. Academy of Management Review, 32(4), 1155-1179. https://doi.org/10.5465/amr.2007.26586086 
Edwards, Anne. (2005). Relational agency: Learning to be a resourceful practitioner. International Journal of Educational Research, 43(3), 168-182.

https://doi.org/10.1016/j.ijer.2006.06.010

Edwards, Anne \& D’ Arcy, Carmen (2004). Relational agency and disposition in sociocultural accounts of learning to teach. Educational Review, 56(2), 147-155. https: / / doi.org/10.1080/0031910410001693236

Flick, Uwe; von Kardoff, Ernst \& Steinke, Ines (Eds.) (2004). A companion to qualitative research. London: Sage Publications Ltd. https://doi.org/10.3126/njqrm.v1i0.1977

Forret, Monica L. \& Dougherty, Thomas W. (2004). Networking Behaviors and Career Outcomes: Differences for Men and Women ? Journal of Organizational Behavior, 25, 419-437. https://doi.org/10.1002/job.253

Gardner, Susan (2009). Student and faculty attributions of attrition in high and lowcompleting doctoral programs in the United States. High Education, 58, 97-112. https://doi.org/10.1007/s10734-008-9184-7

Gibson, Cristina B. (2016). Elaboration, Generalization, Triangulation, and Interpretation: On Enhancing the Value of Mixed Method Research. Organizational Research Methods, 20(2), 193-223. https://doi.org/10.1177/1094428116639133

Goller, Michael \& Harteis, Christian (2014). Employing agency in academic settings: Doctoral candidates shaping their own experiences. In Christian Harteis, Andreas Rausch \& Jürgen Seifried (Eds.), Discourses on Professional Learning. On the Boundary Between Learning and Working (Vol. 9, pp. 189-210). London: Springer. https://doi.org/10.1007/978-94-007-7012-6_1

Greene, Jennifer; Caracelli, Valerie \& Graham, Wendy F, (1989). Toward a Conceptual Framework for Mixed-Method Evaluation Designs. Educational Evaluation and Policy Analysis, 11(3), 255-274. https://doi.org/10.3102/01623737011003255

Hermans, Hubert. (2001a). The Dialogical Self: Toward a Theory of Personal and Cultural Positioning. Culture \& Psychology, 7(3), 243-281. https://doi.org/10.1177/1354067X0173001

Hermans, Hubert. (2001b). The construction of a personal position repertoire: Method and practice. Culture \& Psychology, 7(3), 323-365.

https://doi.org/10.1177/1354067x0173005

Hermans, Hubert (Ed.) (2016). Assessing and stimulating a Dialogical Self in Groups, Teams, Cultures and Organizations. Switzerland: Springer International Publishing. https: / / doi.org/10.1007/978-3-319-32482-1

Hermans, Hubert (2018). Society in the Self. A Theory of Identity in Democracy. New York: Oxford University Press.

Hermans, Hubert \& Gieser, Thorsten. (2012). Handbook of Dialogical Self Theory. Cambridge: Cambridge University Press. https://doi.org/10.1017/cbo9781139030434

Hermans, Hubert \& Hermans-Konopka, Agnesa (2010). Dialogical Self Theory: Positioning and counter-positioning in a globalizing society. Cambridge: Cambridge University Press. https://doi.org/10.1017/CBO9780511712142.001 
Hopwood, Nick (2010a). Doctoral experience and learning from a sociocultural perspective. Studies in Higher Education, 35(7), 829-843.

https://doi.org/10.1080/03075070903348412

Hopwood, Nick (2010b). A sociocultural view of doctoral candidates' relationships and agency. Studies in Continuing Education, 32(2), 103-117.

https://doi.org/10.1080/0158037X.2010.487482

Jairam, Dharmananda \& Kahl, David H. (2012). Navigating the doctoral experience: The role of social support in successful degree completion. International Journal of Doctoral Studies, 7, 311-329. https://doi.org/10.28945/1700

James, William (1890). The Principles of Psychology. Volume I \& II. New York: Henry Holt and Company. https://doi.org/10.1037/11059-000

Jazvac-Martek, Marian; Chen, Shushua \& McAlpine, Lynn (2011). Tracking the doctoral student experience over time: Cultivating agency in diverse spaces. In Lynn McAlpine $\&$ Cheryl Amundsen (Eds.), Doctoral education: Research-based strategies for doctoral candidates, supervisors and administrators (pp. 17-36). The Netherlands: Springer. https://doi.org/10.1007/978-94-007-0507-4

Johnson, Burke; Onwuegbuzie, Anthony J. \& Turner, Lisa A. (2007). Toward a Definition of Mixed Methods Research. Journal of Mixed Methods Research, 1(2), 112-133. https://doi.org/10.1177/1558689806298224

Levecque, Katia; Anseel, Frederik; De Beuckelaer, Alain; Van der Heyden, Johan \& Gisle, Lydia (2017). Work organization and mental health problems in PhD candidates. Research Policy, 46(4), 868-879.

https://doi.org/10.1016/j.respol.2017.02.008

Mayring, Phillip (2004). Qualitative content analysis. In U. Flick, E. von Kardoff, \& I. Steinke (Eds.), A companion to qualitative research (pp. 266-269). London: Sage. https://doi.org/10.3126/njarm.v1i0.1977

McAlpine, Lynn (2013). Doctoral supervision: Not an individual but a collective institutional responsibility. Infancia y Aprendizaje: Journal for the Study of Education and Development, 36(3), 259-280. https://doi.org/10.1174/021037013807533061

McAlpine, Lynn \& McKinnon, Margot (2013). Supervsion - the most variable of variables: Student perspectives. Studies in Continuing Education, 35(3), 265-280. https://doi.org/10.1080/0158037X.2012.746227

McAlpine, Lynn; Paulson, Julia; Gonsalves, Allison \& Jazvac-Martek, Marian (2012). "Untold" doctoral stories: can we move beyond cultural narratives of neglect? Higher Education Research \& Development, 31(4), 511-523. https: / / doi.org/10.1080/07294360.2011.559199

Riazi, Mehdi \& Candlin, Christopher (2014). Mixed-methods in language teaching and learning. Language Teaching, 47(2),135-173. https://doi.org/10.1017/S0261444813000505

Meijers, Frans \& Hermans, Hubert (Eds.) (2018). The Dialogical Self Theory in Education. A multicultural perspective. Cham: Springer International Publishing. https://doi.org/10.1007/978-3-319-62861-5 
Molina-Azorin, José F. (2016). Mixed methods research: An opportunity to improve our studies and our research skills. European Journal of Management and Business Economics, 25(2), 37-38. https://doi.org/10.1016/j.redeen.2016.05.001

Monereo, Carles (2019) The role of critical incidents in the dialogical construction of teacher identity. Analysis of a professional transition case. Learning, Culture and Social Interaction, 20, 4-13. https://doi.org/10.1016/j.lcsi.2017.10.002

Neuendorf, Kimerly A. (2002). The Content Analysis Guidebook. Los Angeles: Sage Publications, Inc. https://doi.org/10.4135/9781071802878

Pilbeam, Colin \& Denyer, David (2009). Lone scholar or community member? The role of student networks in doctoral education. Studies in Higher Education, 34(3), 301 318. https: //doi.org/10.1080/03075070802597077

Pyhältö, Kirsi \& Keskinen, Jenny (2012). Doctoral Candidates' Sense of Relational Agency in Their Scholarly Communities. International Journal of Higher Education, 1(2), 136-149. https://doi.org/10.5430/ijhe.v1n2p136

Pyhältö, Kirsi; Stubb, Jenny, \& Lonka, Kirsti (2009). Developing scholarly communities as learning environments for doctoral candidates. International Journal for Academic Development, 14(3), 221-232. https://doi.org/10.1080/13601440903106551

Pyhältö, Kirsi; Toom, Auli; Stubb, Jenny \& Lonka, Kirsti (2012). Challenges of Becoming a Scholar: A Study of Doctoral Candidates' Problems and Well-Being. ISRN Education, 2012, 1-12. https://doi.org/10.5402/2012/934941

Raggatt, Peter T. F. (2015). Positioning: dialogical voice in mind and culture. Theory \& Psychology, 25(6), 775-797. https://doi.org/10.1177/0959354315590850

Real Decreto 99 / 2011, de 28 de enero, por el que se regulan las enseñanzas oficiales de doctorado. Boletin Oficial del Estado, número 35, de 10 de febrero de 2005. Gobierno de España. Retrieved from:

https://www.boe.es/eli/es/rd/2011/01/28/99/con

Stubb, Jenny; Pyhältö, Kirsi, \& Lonka, Kirsti (2011). Balancing between inspiration and exhaustion: PhD candidates' experienced socio-psychological well-being. Studies in Continuing Education, 33(1), 33-50. https://doi.org/10.1080/0158037X.2010.515572

Sweitzer, Vicky L. (2008). Networking to Develop a Professional Identity: A Look at the First-Semester Experience of Doctoral Candidates in Business. New Directions for Teaching and Learning, 113, 43-56. https://doi.org/10.1002/tl.307

Sweitzer, Vicky L. (2009). Towards a Theory of Doctoral Student Professional Identity Development: A Developmental Networks Approach. The Journal of Higher Education, 80(1), 1-33. https://doi.org/10.1353/jhe.0.0034

Tashakkori, Abbas \& Teddlie, Charles (2010). Handbook of Mixed Methods in Social \& Behavioral Research. Thousand Oaks: Sage. https://doi.org/10.4135/9781506335193

Turner, Gill (2015). Learning to supervise: Four journeys. Innovations in Education and Teaching International, 52(1), 86-98. https://doi.org/10.1080/1470329031000088978

Walsh, John P. \& Lee, You-Na (2015). The bureaucratization of science. Research Policy, 44, 1584-1600. https://doi.org/10.1016/j.respol.2015.04.010 
NÚRIA SUÑÉ-SOLER

Investigadora Post-doctoral en Psicología de la Educación en la Universitat Ramon Llull y Profesora Asociada en la Universitat Oberta de Catalunya.

nursuso@gmail.com

https://orcid.org/0000-0003-2533-3779

\section{CARLES MONEREo FonT}

Catedrático de Psicología de la Educación en la Universitat Autònoma de Barcelona y coordinador del equipo de investigación reconocido SINTE.

carles.monereo@uab.cat

http://orcid.org/0000-0001-7447-985X

\section{AGRADECIMIENTOS}

This research was partially funded by the Spanish Ministry of Economy and Competitiveness (Societal Challenges R+D+i programme FINS-RIDSS -CSO2013-41108-R and Researcher Training programme BES-2014-068397).

\section{FORMATO DE CITACIÓN}

Suñé-Soler, Núria \& Monereo Font, Carles (2020).Doctoral Support Networks: characteristics and associations with research conditions and identity development. Quaderns de Psicologia, 22(2), e1576.

http://dx.doi.org/10.5565/rev/qpsicologia. 1576

HISTORIA EDITORIAL

Recibido: 24-09-2019

Aceptado: 23-03-2020

Publicado: 31-08-2020 